\title{
ПРОБЛЕМЫ ВЫСШЕГО ОБРАЗОВАНИЯ В РОССИЙСКОЙ ФЕДЕРАЦИИ В УСЛОВИЯХ ЦИФРОВОЙ ГЛОБАЛИЗАЦИИ
}

\author{
(c) 2021 Николаева Елена Анатольевна \\ кандидат социологических наук, доцент, кафедра иностранных языков № 3 \\ Российский экономический университет им. Г. В. Плеханова, Россия, Москва \\ E-mail: yoltash82@mail.ru
}

(c) 2021 Воейкова Анна Андреевна

кандидат филологических наук, доцент, кафедра иностранных языков № 3 Российский экономический университет им. Г. В. Плеханова, Россия, Москва E-mail: Voeykova.AN@rea.ru

\section{(c) 2021 Каржанова Наталья Викторовна}

кандидат филологических наук, доцент, кафедра иностранных языков № 3 Российский экономический университет им. Г. В. Плеханова, Россия, Москва

E-mail: knatalya11@mail.ru

\section{(c) 2021 Минова Мария Владимировна}

кандидат филологических наук, доцент, кафедра иностранных языков № 3 Российский экономический университет им. Г. В. Плеханова, Россия, Москва E-mail: Minova.MV@rea.ru

Статья авторов затрагивает вопросы проблематики высшего образования в Российской Федерации в условиях цифровой глобализации. Объектом исследования выступает - высшее образование в Российской Федерации, а предметом - его актуальные проблемы в условиях цифровой глобализации. Теоретическое значение исследования заключено в развитии теории и методологии анализа динамических систем на федеральном уровне. Также теоретическое значение исследования определяется модернизацией методической базы менеджмента в проблемной проекции. Практическое и прикладное значение исследования заключены в систематизации и ранжировании проблем высшего образования в Российской Федерации. Полученные результаты исследования на практике могут быть также применены в целях развития и управления теорией цифровой глобализации.

Ключевые слова: проблемы, высшее образование, Российская Федерация, условия, глобализация, цифровизация.

Система высшего образования в проекции цифровой глобализации [5, с. 47] на сегодняшней мировой арене является ключевым индикатором успешного функционирования большинства развитых стран. Именно поэтому многие исследователи $[2,4]$, зачастую, сопоставляют проблемы развития той или иной страны с проблемами системы ее высшего образования.

В начале 2021 года был представлен рейтинг систем высшего образования [1, 3] ряда стран [6], определенный значениями анализируемого показателя (рейтинговая величина) в годовой проекции (суммарное интегральное значение) за 2020 год. Аналитически обработанные авторами публикации выдержки из данного рейтинга для 14 стран за 2020 год приведены в таблице 1.

Данные таблицы позволяют сделать следующие значимые, по мнению авторов статьи, вы- воды:

- большее значение рейтинговой величины для системы высшего образования определенной страны свидетельствует о наличии в ней минимального количества проблем;

- меньшее значение рейтинговой величины для системы высшего образования определенной страны свидетельствует о наличии в ней максимального количества проблем;

- максимальное значение в рейтинге (82 единицы из 100 возможных) из приведенных стран в 2020 году имело место у системы высшего образования Англии;

- минимальное значение в рейтинге (19 единиц из 100 возможных) из приведенных стран в 2020 году имело место у системы высшего образования Австралии;

- разбег между минимальным (для системы 
Таблица 1. Аналитически обработанные выдержки из рейтинга систем высшего образования для 14 стран в 2020 году

\begin{tabular}{|c|c|c|}
\hline Страна & Рейтинговая величина, ед. & $\begin{array}{c}\text { Динамика относительно 2019 года, } \\
\text { ед. }\end{array}$ \\
\hline Англия & 82 & +4 \\
\hline США & 76 & +2 \\
\hline Франция & 69 & -1 \\
\hline Япония & 65 & +0 \\
\hline Швейцария & 63 & -2 \\
\hline Германия & 62 & +3 \\
\hline Китай & 55 & -2 \\
\hline Сингапур & 53 & +4 \\
\hline Россия & 49 & -5 \\
\hline Канада & 41 & -2 \\
\hline Греция & 38 & +1 \\
\hline Кипр & 27 & +0 \\
\hline Швеция & 23 & -2 \\
\hline Австралия & 19 & +3 \\
\hline
\end{tabular}

высшего образования Австралии) и максимальным (для системы высшего образования Англии) значением рейтинговых величин за анализируемый период времени составил 63 единицы;

- при максимальном значении анализируемого рейтинга в 100 единиц уровень высшего образования в Российской Федерации был оценен менее чем в 50 единиц и уступает таким странам, как Сингапур, Китай, Германия, Швейцария и Япония;

- максимально возможное значение (в рамках аналитически обработанных выдержек) динамики рейтинговой величины (в совокупности +4 единицы) имело место для систем высшего образования таких стран, как Англия и Россия;

- минимально возможное значение (в рамках аналитически обработанных выдержек) динамики рейтинговой величины (в совокупности -5 единиц) имело место для системы высшего образования такой страны, как Канада;

- нейтральное значение (в рамках аналитически обработанных выдержек) динамики рейтинговой величины (в совокупности +0 единиц) имело место для системы высшего образования Швеции и Швейцарии.

Следовательно, исходя из уровня анализируемого рейтинга за 2020 год для системы высшего образования Российской Федерации, относительно других рассмотренных стран, свойственно среднее количество найденных проблем.

Выявленная в целях данной публикации за 2020 год совокупность ключевых проблем системы высшего образования в Российской Федерации приведена в таблице 2 .

Таблица 2. Выявленная в целях данной публикации за 2020 год совокупность ключевых проблем системы высшего образования в Российской Федерации

\begin{tabular}{|c|c|}
\hline Наименование проблемы & Характеристика проблемы \\
\hline $\begin{array}{l}\text { Недостаточный уровень финансиро- } \\
\text { вания существующих инициатив }\end{array}$ & $\begin{array}{l}\text { Объем финансирования системы высшего образования в Россий- } \\
\text { ской Федерации является одним из наиболее низких в рассматрива- } \\
\text { емом перечне стран }\end{array}$ \\
\hline $\begin{array}{l}\text { Высокий уровень централизации } \\
\text { принимаемых решений }\end{array}$ & $\begin{array}{l}\text { Практически все без исключения ключевые решения в области } \\
\text { высшего образования в Российской Федерации принимаются пре- } \\
\text { имущественно централизованным методом (количество решений, } \\
\text { принимаемых децентрализованным методом достаточно мало) }\end{array}$ \\
\hline $\begin{array}{l}\text { Недостаточная эффективность прини- } \\
\text { маемых стратегических решений }\end{array}$ & $\begin{array}{l}\text { По данным ряда консалтинговых компаний эффективность прини- } \\
\text { маемых стратегических решений в Российской Федерации в сфере } \\
\text { высшего образования в } 2020 \text { году может быть оценена как средняя }\end{array}$ \\
\hline $\begin{array}{l}\text { Низкая эффективность существующих } \\
\text { механизмов распределения имею- } \\
\text { щихся инвестиционных ресурсов }\end{array}$ & $\begin{array}{l}\text { Консалтинговая компания Ernst\&Young [6] несколько лет подряд } \\
\text { (включая } 2020 \text { год) оценивала эффективность инвестиций в системе } \\
\text { высшего образования в Российской Федерации, относительно стран- } \\
\text { лидеров, как низкий }\end{array}$ \\
\hline
\end{tabular}


Продолжение Таблицы 2

\begin{tabular}{|l|l|}
\hline $\begin{array}{l}\text { Низкий уровень платежеспособности } \\
\text { обучащихя }\end{array}$ & $\begin{array}{l}\text { Рейтинг платежеспособности обучающихся в Российской Феде- } \\
\text { рации, ввиду низкого уровня жизни подавляюего большинства } \\
\text { населения, в 2020 году был оценен как низкий }\end{array}$ \\
\hline $\begin{array}{l}\text { Недостаточный уровень качества } \\
\text { существующрамм образовательных }\end{array}$ & $\begin{array}{l}\text { Уровень качества образовательных программ в Российской Федера- } \\
\text { ции является достаточно дифференцированным и напрямую зави- } \\
\text { сит от конкретного региона (высокий уровень качества имеет место, } \\
\text { преимущественно, лишь в центральных регионах) }\end{array}$ \\
\hline $\begin{array}{l}\text { Сложность согласования и внедрения } \\
\text { передовых инициатив }\end{array}$ & $\begin{array}{l}\text { По предварительным оценкам уровень проницаемости передовых } \\
\text { инициатив в систему высшего образования в Российской Федерации } \\
\text { в различных проекциях (информационная, техническая, кадровая } \\
\text { и прочие) в 2020 году (как и в прочих периодах) являлся достаточно } \\
\text { низким }\end{array}$ \\
\hline $\begin{array}{l}\text { Относительно низкий уровень обе- } \\
\text { спеченности передовыми информа- } \\
\text { ционными технологиями }\end{array}$ & $\begin{array}{l}\text { Более 30 процентов высших учебных заведений в Российской Фе- } \\
\text { дерации в 2020 году не имели единой системы информационного } \\
\text { обеспечения и функцинировали при внедрении чрезвычайного } \\
\text { положения, вызванного распространением коронавирусной инфек- } \\
\text { ции, в условиях частичной информационной блокады }\end{array}$ \\
\hline
\end{tabular}

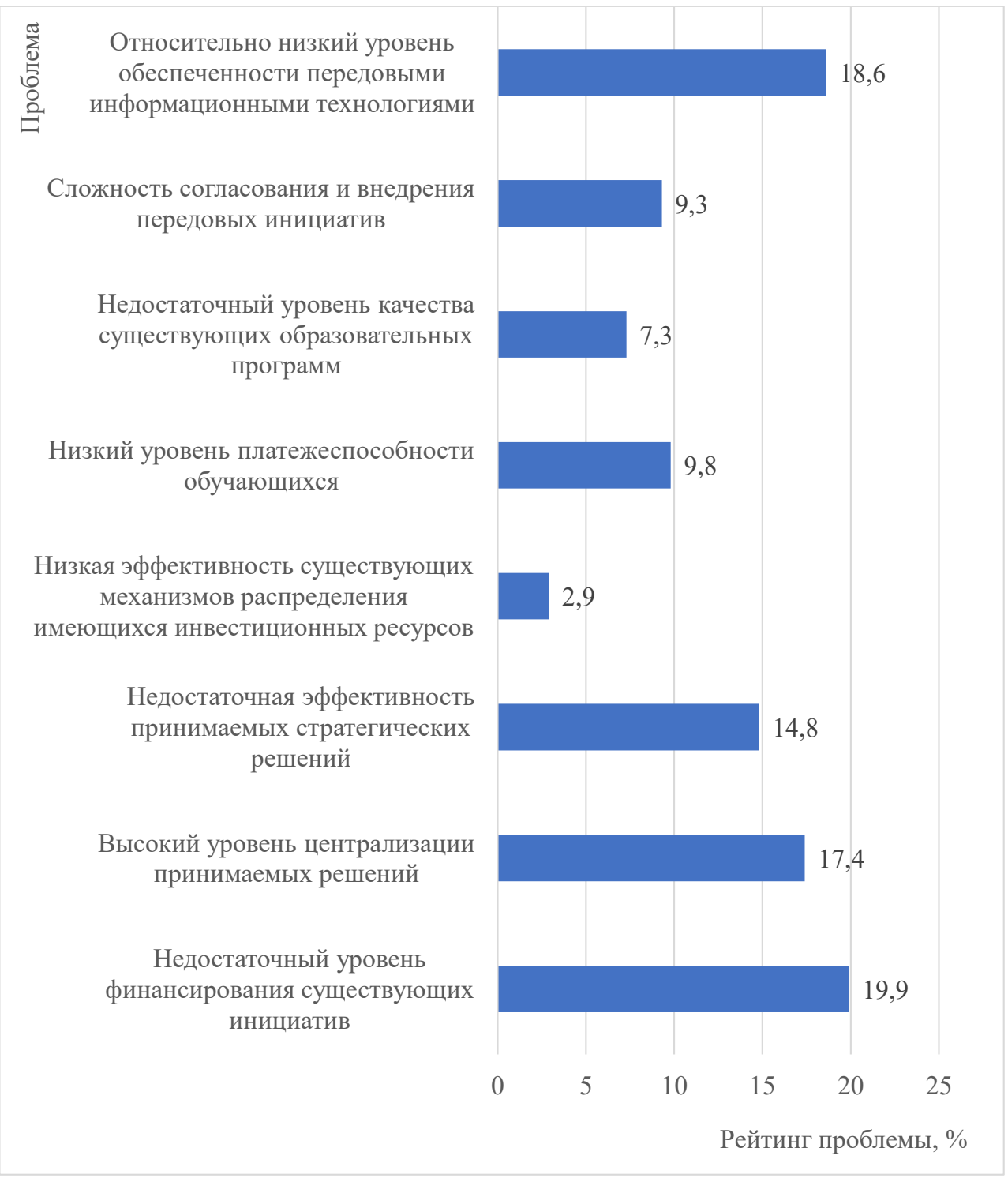

Puc. 1. Составленный авторами данной публикации рейтинг анализируемых для системы высшего образования в Российской Федерации проблем (относительное распределение), актуальный на начало 2021 года 
Составленный авторами данной публикации рейтинг анализируемых для системы высшего образования в Российской Федерации проблем (относительное распределение), актуальный на начало 2021 года приведен на рисунке 1.

Из рисунка можно увидеть, что наиболее значимой (рейтинг значимости равен 19,9 процентам из 100 процентов) в рамках анализируемого перечня является проблема, связанная с недостаточным уровнем финансирования существующих инициатив. Чуть меньший уровень значимости имел место для проблемы относительно низкого уровня обеспеченности информационными технологиями (рейтинг значимости порядка 18,6 процентов).

Несколько выше или практически на уровне 15 процентного интервала значимости следовали проблемы «высокий уровень централизации принимаемых решений» (17,4 процента) и «недостаточная эффективность принимаемых стратегических решений» (14,8 процентов).

Проблемы «низкий уровень платежеспособ- ности обучающихся», «сложность согласования и внедрения передовых инициатив», «недостаточный уровень качества существующих образовательных программ» и «низкая эффективность существующих механизмов распределения имеющихся инвестиционных ресурсов» находились локально значительно ниже 15 процентного интервала.

Таким образом, можно отметить, что система высшего образования в Российской Федерации функционирует при наличии целого ряда значимых проблем, совокупность которых не позволяет ей эффективно конкурировать с более развитыми странами в условиях цифровой глобализации.

Для разрешения сложившейся ситуации, по мнению авторов, имеет смысл комплексным образом пересмотреть подход к управлению высшим образованием в целом ориентируясь на передовой опыт развитых стран, сбалансированно адаптируя его под текущие потребности Российской Федерации.

\section{Библиографический список}

1. Найденко И. С., Величко О.А. Проблемы и перспективы развития внедрения цифровых технологий в высшем образовании / И.С. Найденко, О.А. Величко / Гуманитарный научный вестник - Смоленск: Изд-во: «ООО «Смоленский социологический центр» (Смоленск)», 2020. - № 5.- С. 209-214.

2. Николаева Е. А., Кузнецова Ю.А., Сидорова Е.Е., СоколоваЕ.И. Проблемы оценки качества образования в высшей школе в условиях перехода на дистанционное обучение в Российской Федерации / Е. А. Николаева, Ю. А. Кузнецова, Е.Е. Сидорова, Е.И. Соколова / Экономические науки - Москва: Изд-во: «ООО «24 Принт», 2020. - № 190.- C. 47-50.

3. Пономаренко Е. Е., Прохорова Е.А. и др. Проблемы и перспективы модернизации экономики высшего образования в условиях цифровизации / Е. Е. Пономаренко, Е. А. Прохорова, Д. А. Розанов, О. С. Жирина / Экономика устойчивого развития - Краснодар: Изд-во: «Общественная академия инновационного устойчивого развития (Краснодар)», 2020. - № 1.- С. 143-146.

4. Фейгин А. В. Проблемы высшего образования / А. В. Фейгин / Studnet - Москва: Изд-во: «Фомин Александр Анатольевич (Москва)», 2020.- № 7.- С. 504-508.

5. Шепелова Н. С., Шепелов Н. Н. Основные проблемы цифровой трансформации высшего образования в России / Н. С. Шепелова, Н. Н.Шепелов / Экономические исследования и разработки - Нижний Новгород: Издво: «Индивидуальный предприниматель Краснова Наталья Александровна», 2020. - № 2. - С. 46-52.

6. Компания «Ernst\&Young» [Электронный ресурс]: аналитические материалы - Официальный сайт компании «Ernst\&Young», 2021. - Режим доступа: https://www.ey.com/ru_ru 